\author{
TWO HUNDRED AND FIFTEENTH SCIENTIFIC MEETING \\ EIGHTY-SIXTH SCOTTISH MEETING \\ WEST LECTURE THEATRE, UNIVERSIT'Y OF EDINBURGH MEDICAL SCHOOL \\ TEVIOT PLACE, EDINBURGH
}

25 OCTOBER 1969

\title{
THE USE OF THE COMPUTER IN NUTRITION
}

\author{
Chairman : Dr D. H. ReEs, BSc, ARCS, \\ Rothamsted Experimental Station, Harpenden, Herts

\section{The first computer at a nutritional research institute: how its use has evolved}

\section{By A. W. Boyne, Rozvett Research Institute, Bucksburn, Aberdeen, $A B z 9 S B$}

The background to the installation of a digital computer at the Rowett Research Institute is that there has been a Biometry Department since 1948. The function of this department has evolved naturally over the years until before the acquisition of the computer when it consisted of two scientific officers, one experimental officer and three machine operators. Over the last 15 years or so it has been customary for consultation to take place between research workers and the Biometry Department on the rationale and design characteristics of projected experiments. Within the Biometry Department a formal design is prepared for each agreed experiment along with specific questions which the experiment is intended to answer. The experiment is identified by number, and a copy of the design retained in Biometry pending the completion of the experiment. On completion the data are analysed by the Biometry Department and a report is written summarizing the conclusions in terms of the stated aims of the experiment, and giving, in addition, information on various aspects of variability.

With the steady increase in numbers of research workers in the Institute, and the development of equipment designed to speed up various analytical measurements the work involved in the Biometry Department has increased over the years.

In addition to the electric calculators in the Biometry Department, seventeen others were sited throughout the Institute and were about $75 \%$ fully occupied on various routine calculations. Hand machines were also employed and a survey made in 1965 indicated that, at a very conservative estimate, over 400 man hours weekly were occupied in routine calculations of one kind or another. We recognized that many of these calculations were too slight to warrant programming, punching and checking, but clearly there were many for which the use of a computer would be advantageous. The calculations involved in determinations of nitrogen and other entities, in respiration calorimetry and in metabolic trials, to name a few, come into this category.

A third factor entered into our decision that a computer was necessary. Over the last to years there had been advances in automated analysis-of particular import- 
ance in our work were automated amino acid and fatty acid analyses and work with isotopes using the scintillation counter.

In summary, there were three main uses for which we considered a computer would be at least beneficial, and in their order of importance they were:

(I) as an aid in routine computations,

(2) to handle output from automated analytical equipment,

(3) to take over some of the statistical computations from the Biometry Department.

\section{Preparation for installation}

Having had our case accepted for the need for a computer we eventually decided on an IBM I I 30 with $8 \mathrm{~K}$ core store (the largest available at that time) with backing disk, line printer and using punched cards as the primary input. To meet our papertape requirements we decided on a Facit Ohdner paper tape reader with a speed of 500 characters/s. We also ordered four 029 printing punches for programme and primary data preparation.

The initial installation was expected in December 1967 , but for a number of reasons the complete system was not fully installed and functional until May i 968 , and as a result of the delay we did not obtain maximum benefit from the preparations which the Biometry Department had made to familiarize Institute staff with various aspects of computer usage. These were that we took advantage of several of the courses offered by the manufacturer dealing with familiarization, and with operating our system, also with the subset of Fortran IV used on the I 330 , and with its lowlevel language, Assembler. These are typical of courses offered by most manufacturers. We also obtained sets of manuals on these topics and of a programmed instruction course in Fortran IV.

In late September 1967 , we prepared on the basis of these courses and manuals a 2-week course of instruction for members of Institute staff dealing with programming and data preparation appropriate for the type of routine calculations being done on our desk calculators. Some forty-seven members of staff completed this course, which attempted specifically to synthesize into a coherent whole the pieces of information which tended to be dispersed throughout the company's documents. The Biometry Department also organized instruction to some forty members of staff in the use of the 029 card punch. This was done in October I967.

If the computer had been available in December, as expected, it would have been possible for Institute staff to test, after a relatively short delay, the techniques in which they had received instruction. In the event, some ten members of staff outwith the Biometry Department have successfully written and run their own programmes.

These steps which we had taken so far stemmed from deliberate policy as it was our intention to run an open system to which all had access. In addition, those who did not intend to write their own programmes should have an understanding of the principles involved. Also as we are a small Institute, employing a small computer we decided to use printing punches which would facilitate immediate check by 
reading of punched data instead of using punch and verifier and employment of the specialist staff necessary to justify their purchase. In addition we have provided the facility via a stored programme of having all data printed out on the line printer.

\section{Growth and types of use}

Over the last year more than roo programmes and subroutines were written in the Biometry Department and the use of the computer steadily increased as shown in Fig. I in which the hours during which the central processing unit (CPU) is operating are plotted weekly. These rose steadily until April 1969 when the CPU time was about $23 \mathrm{~h}$ weekly. The subsequent fall to the lower level of $15 \mathrm{~h}$ was occasioned by

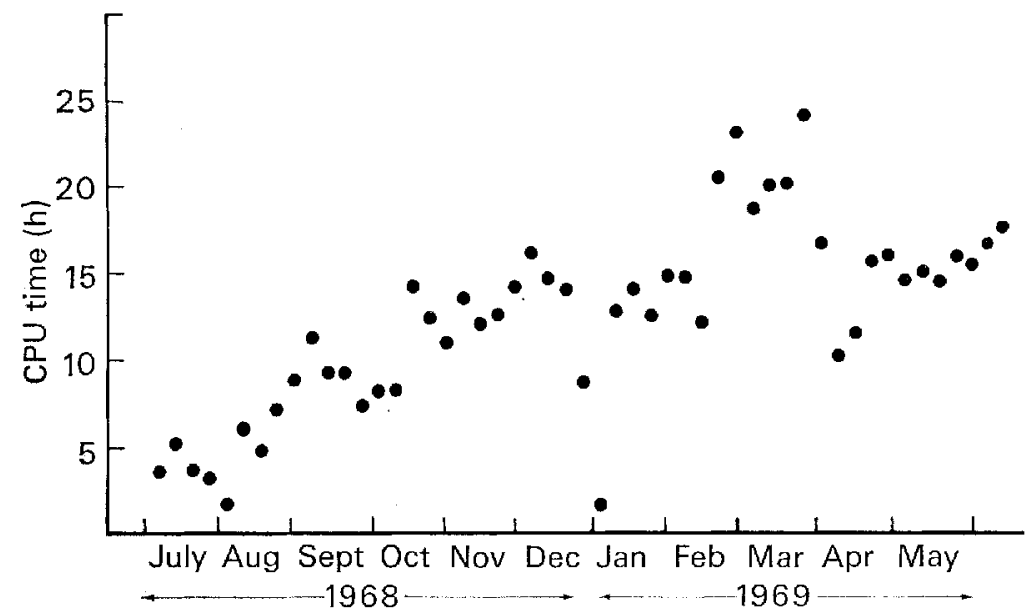

Fig. I. Weekly use of computer in terms of hours logged on central processing unit (CPU). As a rough guide, on average $\mathrm{I} h$ of CPU time approximates to $2 \mathrm{~h}$ use.

suspension of amino acid data-logging, for reasons unconnected with the computer. This lower level has been maintained over the summer months, but intensity of use is beginning to increase again with the end of the summer holiday season. About $50-60 \%$ of the CPU time has been taken up by programme development.

Changes within the Biometry Department occasioned by the increase in computer use were that progressively less use was made of desk calculators for statistical calculations, so much so that two machine operators are now employed instead of three, and those two spend a substantial part of their time as card punch operators, punching programmes and data cards for Biometry and other departments of the Institute; also there was an increasing demand throughout the Institute for guidance in programme writing and various aspects of computer operation. This demand has been met by employment of an Experimental Officer with experience in computer operations.

The allocation of time for various computer activities is not completely rigid, but operates within a frame of 3 half-hour periods daily 09.00-09.30, I I.00-I I.30 and $15.00-15.30 \mathrm{~h}$ for programme development by Institute staff, the rest of the day 
being used by Biometry for production runs, and its own programme development.

In devising programmes to carry out routine calculations, we have concentrated on those which would save most time. Typical is $\mathrm{CCRC}_{3}$, a programme to take the output of a day's run in a respiration chamber, from which it calculates daily $\mathrm{O}_{2}$ consumption, $\mathrm{CO}_{2}, \mathrm{CH}_{4}$ and water vapour production, and daily heat production. In order to do this a number of tedious corrections for temperature, pressure and humidity have to be made. These calculations occupy over $30 \mathrm{~min}$ on a desk calculator and just over I $s$ on the computer plus less than 2 min to punch and check the appropriate data card.

Description of our data-logging programmes would occupy too much space for this paper. So far three have been written, one for lipid analysis, another for amino acid analysis, both of which accommodate paper-tape input, and a third deals with the output from a Packard scintillation counter automatically punched on cards. Other programmes are being developed to handle data from respiration chambers and the gradient-layer calorimeter.

In writing our programmes for statistical analyses we have tended to write a large number of small programmes each for a specific task rather than general programmes to cover a number of different possible situations. The reasons for this are to avoid straining the limited core size available ( $8 \mathrm{~K})$ and to simplify the task of the potential user in applying correctly the conventions for each type of programme. We have, for example, separate programmes for slope ratio assays, parallel line assays, analyses of latin squares, and of randomized blocks. Other programmes are being developed or are projected but it should be noted that our major initial programming effort has been directed towards routine calculations and data-logging projects.

However, it is useful to make mention of $\mathrm{RB}$, the randomized block programme, written by Mr I. McDonald of the Biometry Department. This programme illustrates how with a computer it is feasible to carry out exact analyses where the work would often be too time-consuming on desk calculators. It analyses RB's of any size up to $36 \times 36$. Missing values are fitted by an iterative process, and the programme uses the 'Yates' approximation for calculating standard errors of differences between means. In addition, analyses are carried out to provide unbiased estimates of row and column mean squares. The usual analysis carried out on desk calculators does not obtain unbiased estimates of these two factors.

\section{General availability of programmes, and routine for punching data}

In developing the use of our system we wished to ensure that programmes written should be as widely available as possible, and that punching of data should be as error-free and as speedily executed as possible. To achieve wide availability of programme we have evolved a system whereby the authors of programmes which are frequently used are required to write a note on each which describes precisely its purpose and the exact mode of use. This information is punched on cards which are kept, indexed, in a cabinet. As a check on the compliance of authors with these instructions a dumplet is obtained at regular intervals to check on programmes which have been stored on disk. A very simple programme called TELME is stored 
on disk so that the intending user of a programme can have a print-out of its purpose and mode of use. In the computer-room a record book is maintained with an index of programmes and a brief description of their uses. The TELME listing obtained for each programme is also contained in this book.

In practice the worker would consult the index to see whether a programme appears to meet his requirements and he would confirm this by turning to the TELME print-out for this programme. If the instructions are relatively brief he might simply copy them from the book there and then; if on the other hand they are lengthy he will obtain the TELME cards from the cabinet and process them by programme TELME obtaining one or more copies to take away with him and implement the instructions at leisure. An example of a very simple TELME listing is given in Fig. 2. This is for a programme called PLOXY to plot up to 200 points, using as many as twenty different symbols to represent, for example, treatment groups or litters.

SUBROUTINE PLOXY

PURPOSE

TO PLOT UP TO 200 POINTS ON A SINGLE PAGE FROM LINE PRINTER. UP TO 20 OIFFERENT SYMBOLS MAY BE USED TO INDICATE TREATMENTS, LITTERS, ETC. THE SCALES USED IN PLOTTING ARE DETERMINED BY THE DATA. SINCE THIS PROGRAM REQUIRES A COMPLETE PAGE FOR O/P. THE USER MUST PREPARE HIS OWN HEADINGS WITHIN HIS OWN PROGRAM.

IF TWO OR MORE POINTS OCCUR AT THE SAME POSITION, AND THEY ARE IN THE SAME TREATMENT GROUP, THEY ARE REPRESENTED BY ONE SYMBOL ONLY. IF, HOWEVER, THE POINTS ARE FROM DIFFERENT TREATMENT GROUPS THEN AT THE POINT ON THE GRAPH THE SYMBOLS FOR EVERY TREATMENT REPRESENTED ARE SUPERPOSED. IT IS THEREFORE SUGGESTED THAT CLEARLY DISTINGUISHABLE SYMBOLS BE USED, SUCH AS ' $O$ ', ' $X$ ', ' ' + ', ETC.

USE

1. THE STATEMENT REQUIRED IS

CALL PLOXY\{X,Y,NT,N,LLANK,LSK,LYM,NSYM\}

$X$ IS THE NAME OF THE REAL VARIABLE ALONG THE HORIZONTAL AXIS

$Y \quad$ IS THE NAME OF THE REAL VARIABLE ALONG THE VERTICAL AXIS

NT IS THE ARRAY OF TREATMENT (OFi LITTER ETC) NOS.ASSOCIATED WITH EACH POINT

N IS THE NUMBER OF POINTS TO BE PLOTTED

LLANK IS THE BLANK CHARACTER USED TO ENSURE THAT NO POINT IS PLOTTED UNINTENTIONALLY

LSK IS A CHARACTER USED TO INDICATE SCALE POINTS ALONG BOTH AXES

LYM IS THE NAME OF THE ARRAY OF SYMBOLS CHOSEN BY THE USER TO REPRESENT THE TREATMENTS (OR LITTERS,ETC)

NSYM IS THE NUMBER OF SYMBOLS USED IN THE GRAPH (EQUIV. TO NOS, OF TREATMENTS广.

2. THE USING PROGRAM MAY HAVE A STATEMENT READING LLANK, LSK AND LYM, AND A

CARD TO BE READ ON WHICH THEY ARE PUNCHED E.G.

READ $(2,222)$ LLANK,LSK, (LYM $(J), J=1$, NSYM $)$

222 FORMAT (40A1)

AT THE APPROPRIATE PLACE IN THE DATA CARD DECK, A CARD MUST THEN BE INSERTED CONFORMING TO STATEMENT 222. IF FOR EXAMPLE THERE WERE 4 TREATMENTS SO THAT NYSM=4, THE DATA CARD MIGHT BE PUNCHED THUS

(NOTE BLANK IN CCV)

$\begin{array}{ccccccc}\mathrm{CC} & 1 & 2 & 3 & 4 & 5 & 6 \\ \text { SYMBOL } & & * & \mathrm{X} & 0 & * & +\end{array}$

3. ALTERNATIVELY. THE USING PROGRAM MAY INCLUDE STATEMENTS SETTING LLANK,LSK,AND THE MEMBERS OF THE ARRAY LYM TO INTEGER VALUES EOUIVALENT TO THE SYMBOLS REQUIRED.

Fig. 2. An example of a TELME print-out. The TELME for any programme describes the purpose for which it has been written and gives instruction on how to use it. 
CCRC3

Closed Circuit Respiration Chamber Work Sheet

9

Chamber Number

Animal Number

Experiment Number

Period Number

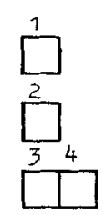

Day Number
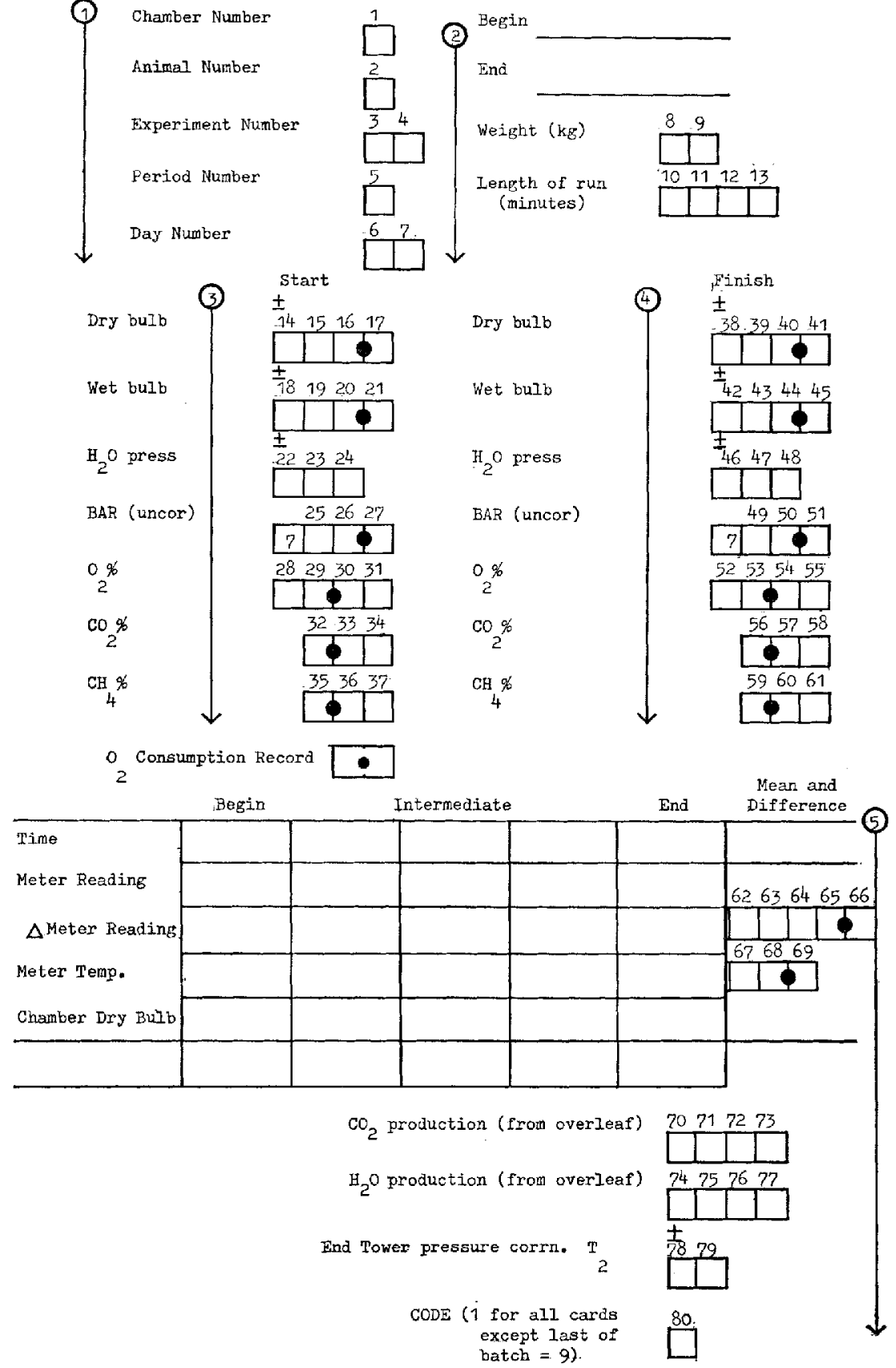

Fig. 3. A typical proforma prepared as a source document for punching data on to cards. The column numbers refer to columns on the punch cards and decimal points are indicated as necessary. 
The aids to easy and accurate punching are twofold. For as many programmes as practicable, proformas are prepared where card columns are identified and the entries to be made in each group of columns corresponding to the value of a variable are clearly defined. Fig. 3 gives a typical proforma used for the closed circuit respiration chamber programme, $\mathrm{CCRC}_{3}$. Note that the decimal points are not punched but are clearly marked on the proforma. As mentioned above, a programme VIEW may be applied to any data so that a print-out is obtained of the data punched on a deck of cards. This is particularly useful for large decks of cards which are to be processed by lengthy programmes, as it prevents unnecessary waste of computer time.

In recent months we have noted with the increase in proforma use that an increasing proportion of punching is carried out by members of Biometry staff. Currently a scheme is being developed to process all the pig herd records by computer, and there is a throughput of about 3000 pigs annually. If this is successful the scheme will be extended to the other farm animals, in which event we shall probably increase our strength by one punch operator and shall then do virtually all punching within the Biometry Department. If this happens it is quite possible that a change will be made to the use of punch and verifier.

\title{
Diet assessment and formulation in human nutrition
}

\author{
By D. S. Miller and Pamela Mumford, Queen Elizabeth College, London, W8
}

Our paper is essentially a pragmatic one. We doubt if we can impress programmers on programming or nutritionists on nutrition. What we can try to do is to show how we have applied computing to our nutritional problems and hope that our experiences might be useful to others in similar circumstances. However, in order to avoid presenting simply a list of programmes which we have found successful we have attempted to draw out some general principles of approaching nutritional problems in which one can use a computer, and to outline our philosophy for criticism and discussion.

\section{Training and operation}

Some years ago we became interested in the results of gluttony in man, and we decided to overfeed ourselves. This involved determining our nutrient intake for a period of 20 weeks, and one of us was forced to spend half her time in calculating only four nutrients. We planned to call for at least twelve volunteers to extend the work, and it was quite clear we were not going to be able to do the calculations with our personnel. It is true that we could have designed our experiment in a way that all subjects were fed an indentical diet thereby reducing the arithmetic, but the extent of overfeeding each individual would have been different depending upon 